\title{
COMMENT
}

\section{Reflective narratives during the Covid-19 pandemic: an outlet for medical students in uncertain times}

\author{
MANJULIKA VAZ
}

\begin{abstract}
Reflective narratives on personal experiences, observations, thoughts and concerns were used as a method of helping medical students process the Covid-19 pandemic and their lives. This involved individual writing, anonymous submission, on-line group reading of selected narratives on a voluntary basis and facilitated discussions. Students felt that this was a safe method to voice their feelings and thoughts, to understand themselves better and to gain new perspectives. Though small numbers of students participated, there appears to be a greater potential to use reflective narrative writing coupled with facilitated group discussions in medical education to help students cope with external and internal stress, to better understand themselves, to relate to others and possibly to become more empathic.
\end{abstract}

Keywords: Education, medical, reflective narrative, Covid-19, wellbeing strategies, humanities, medical students.

The "novel" coronavirus outbreak refers to more than a new zoonotic disease. It has shut down large parts of the world and caused death and hardship on a scale never seen by at least a couple of generations. Medical history textbooks, fictionalised novels and documentaries remind us that this has happened before; with the Spanish Flu (1918 - 20) and the Black Plague (1346 - 53), among others. More recent viral epidemics, like SARS and Ebola were more localised, more contained and less fatal, at least in absolute numbers. So, Covid 19, with over 200 countries affected and almost twenty million cases and counting and over seven hundred thousand confirmed deaths worldwide (1), is a new and daunting phenomenon that has affected both medical and non-medical people alike.

Author: Manjulika Vaz (manjulikavaz@sjri.res.in), Division of Health and Humanities, St John's Research Institute, St John's Medical College, Sarjapur Road, Bengaluru 560 034, INDIA.

To cite: Vaz M. Reflective narratives during the Covid pandemic: an outlet for medical students in uncertain times. Indian J Med Ethics. 2022 Jan-Mar; 7(1) NS: 62-64.

Published online on June 22, 2021.DOI: 10.20529/IJME.2021.048.

Manuscript Editor: Rakhi Ghoshal

(c) Indian Journal of Medical Ethics 2022

\section{Response to the Covid pandemic and its impact on medical students}

In India, we had a national lockdown from March 24, 2020, to April 21, extended to May 4, 2020, and then a partial lockdown to May 17, 2020. There have been ongoing localised lockdowns in areas where cases are clustered. All medical colleges suspended classes, sent students back to their homes and vacated hostels. By mid-April, various online teaching platforms were experimented with and medical students began remote classes with faculty following a timetable. However, specific challenges remained - the inadequacy of on-line methods for practicals and clinical teaching, and the challenges of examinations and assessments - particularly so for the first-year students who were enrolled in a new competency-based curriculum, initiated by the Medical Council of India in 2019 (2).

\section{The role of reflective narratives during the Covid pandemic}

The Health and Humanities Division of St. John's Medical College promotes the idea of the humanities in health among healthcare practitioners and students-in-training through various classes and activities. Workshops and events have been held earlier to promote reflective narratives as a means to process experiences and observations. During the lockdown periods, the Division with the student-driven groups "Quillosophical Society" (which aims to encourage individual thought and voices through the written and spoken word) and the Humanities Club (which aims to foster health-related humanities disciplines through educative, reflective and research activities), announced two reflective narrative events - "Small virus, Big impact" in early April and "Mind Matters" in early May 2020. Twenty students participated in the first and 25 in the second event. Students were encouraged to reflect on their current situations, process their personal stories, their emotions and their perspectives in the form of a reflective essay, a play script or poetry. Students were made aware that this was not "creative writing" and that their submissions needed to be personal and original. Interestingly, not all narratives written by the students related to the topic - some reflected on their general thoughts and concerns. Students were allowed to send in their submissions anonymously, and could opt to read the piece themselves or for it to be read by someone 
else in the online events that were subsequently planned. All students gave permission for parts of their narratives to be used in this publication.

The students in the early years of medicine, focused their writing on their loss of peer contact, the emotions of being isolated at home, a questioning of the lockdown and its consequences, a need for compassion and a shift from themselves to the pain of others, both physical, psychological and moral.

The perspectives of interns were more related to their handson work with patients and communities and related to moral distress. They had to deal with dilemmas and ethical issues about mask wearing, understanding the uncertainties of Covid-19 and the financial and transport challenges of patients during the lockdown.

Introspection and reflective methods help those grappling with ambiguities and constantly changing understanding and explanations of a phenomenon (3). This was reflected in the feedback received following the events. Students said that they participated in the reflective writing exercises to voice their thoughts on the pandemic, to express and share their emotions through the medium of writing, because they love to write, and that the theme was current and relatable.

The on-line reading and discussion sessions that followed also helped these students to "understand the current situation", "helped go deeper and introspect" and "gain a new perspective".

Interestingly, the perspectives gained were those of "the other" also born out of personal experience and observation. These included a recognition of the privilege of being part of the educated urban middle class; the interconnectedness of life and the natural environment, human biology and human life irrespective of country, class, creed or community; and finally the resilience and creativity shown by different people in coping with constraints and managing their lives. Students also shared that through these sessions they had a "safe space" to tell their stories and that this process was therapeutic. The cathartic aspect of articulating personal reflections by healthcare workers has been a powerful and useful tool during the Covid-19 pandemic in hospital settings as well (4). Handling anxieties, mental stress and feelings of not being in control were best articulated in this private manner than formally to supervisors. However, hospital managements were able to address hospital protocols and the mental health of their staff through these narratives (4).

\section{The wider implications of reflective narratives in medicine}

The above benefits of these reflective narrative initiatives on the personal perspectives of medical students reinforce the already established advantages of narrative medicine (which focusses on wider relationships, and not just biological factors, in the causes and healing of diseases) in the teaching of medicine. These include an appreciation of diverse perspectives on complex events, an ability to handle uncertainty, to nurture empathy and to gauge the societal and ethical dimensions of events $(5,6,7)$. It is also said that more than illness itself, it is the stories and experiences of being ill, and the experiences of being cared for that aid and hasten the recovery process $(7,8)$. In contrast, "modern medicine" with its focus on facts, findings and technology often side-lines the unique voice, feelings and circumstances of the individual.

\section{Narrative medicine needs attention.}

The process involved in narrative medicine, however, requires skill, sensitivity and patience. Reflective writing during the pandemic and on-line narrative reading and discussions have helped to keep the students connected with each other, unburden their emotions, handle the stress of isolation and uncertainty and form their own opinions and perspectives of the pandemic. And, even while students grapple with their own state, reflective narratives encourage them to recognise the "other" and "feel with them" $(5,9)$. Teaching empathy is not easy - some would argue that it is impossible in a classroom, but exercises like writing reflective narratives on something as personal and universal as the impact of the pandemic, has value in this direction (4, $10)$.

\section{Limitations of replicability and lessons for the future}

Writing has its challenges. It must be noted that the routinisation of "student narratives" as a learning method in the new AETCOM module of the Medical Council of India (11) has its dangers. Not everyone is comfortable about sharing personal reflections and not everyone writes best in English. Thus, there were small numbers that responded to these sessions. This is not to say that this limitation should negate the benefit accrued to those who did participate. The feedback has been encouraging. Hesitation about writing, the limitation of language and the inhibition of sharing can possibly be addressed by introducing classes on narrative writing, allowing for writing in the regional languages and exploring other formats of sharing such as blogs and talking books. The element of hearing others' stories and of interacting with others with a facilitator seems important to hold on to (12). Blind insistence on narrative writing without facilitator skills can lead to the well-known fallouts of students copying from each other or cleverly plagiarising online content in order to be graded well. Other media such as art or theatre could also be explored. While the student reflections revealed that a small virus has a big impact, we conclude that we have made small beginnings with reflective narrative writing with the long-term hope of expansion, of replication, of skill development and ultimately, of helping develop more self-aware, sensitive and empathic doctors. 


\section{Acknowledgements}

The students of the Quillosophical Society and the Humanities Club of St John's Medical College Bangalore are thanked for their active involvement in organising and participating in the reflective narrative events. An opportunity to talk about these events was provided by the 8th National Bioethics Conference on the theme, "Crisis within a crisis: Scientific, ethical \& humanitarian challenges of Covid-19" on December 19, 2020.

\section{References}

1. WHO Coronavirus Disease (COVID-19) Dashboard. Geneva: WHO; 2020 Aug [cited2020 Aug 6]. Available from: https://covid19.who.int/.

2. Medical Council of India. Competency Based Assessment Module for Undergraduate Medical Education Training. New Delhi: MCl; 2019 [cited 2020 Aug 6]. Available from: https://mciindia.org/CMS/wpcontent/uploads/2019/10/

Module Competence based_02.09.2019.pdf.

3. Wear D, Zarconi J, Garden R, Jones T. Reflection in/and writing: pedagogy and practice in medical education. Acad Med. 2012[cited 2020 Aug 6]; 87(5), 603-9. Available from: https://doi.org/10.1097/ACM. 0b013e31824d22e9

4. Daphna-Tekoah S, Megadasi Brikman T, Scheier E, Balla U. Listening to hospital personnel's narratives during the COVID-19 outbreak. Int J Environ Res Public Health. 2020 Sep 3;17(17):6413. Doi:10.3390/ ijerph17176413.
5. Miller E, Balmer D, Hermann N, Graham G, Charon R. Sounding narrative medicine: studying students' professional identity development at Columbia University College of Physicians and Surgeons. Acad Med. 2014;89(2):335-42. Doi:10.1097/ACM. 0000000000000098

6. Charon R. The patient-physician relationship. Narrative medicine: a model for empathy, reflection, profession, and trust. JAMA. 2001 Oct 17;286(15):1897-902. doi: 10.1001/jama.286.15.1897..

7. Arntfield SL, Slesar K, Dickson J, Charon R. Narrative medicine as a means of training medical students toward residency competencies. Patient Educ Couns. 2013 Jun;91(3):280-6. Doi: 10.1016/j.pec. 2013.01.014. Epub 2013 Feb 23.

8. Mehl-Madrona L. Narrative Medicine: The Use of History and Story in the Healing Process. Rochester, Vermont: Bear \& Company; 2007. 324 pages,

9. Mehl-Madrona L. The nature of narrative medicine. Perm J. 2007;11(3):83-6. Doi:10.7812/tpp/07-052

10. Huang $Y$, Mongoose LV, Huang C. The influence of narrative medicine on medical students' readiness for holistic care practice: a realist synthesis protocol. BMJ Open 2019;9: e029588. Doi: 10.1136/ bmjopen-2019-029588

11. Medical Council of India. Attitude, Ethics and Communication (AETCOM) Competencies for the Indian Medical Graduate. New Delhi: MCl; 2018[cited 2020 August 7]. Available from: https:// www.mciindia.org/CMS/wp-content/uploads/2020/01/ AETCOM_book.pdf,

12. Diorio C, Nowaczyk M. Half As Sad: A plea for narrative medicine in pediatric residency training. Pediatrics. 2019 Jan; 143(1):e20183109. doi: 10.1542/peds.2018-3109. Epub 2018 Dec 6.

\section{Advertise with us}

IJME welcomes advertisements for the print issue as well as the website. The guidelines, tariff details, and payment details are available at https://ijme.in/advertise/. The advertisement spaces for the website are available on the landing page and can be viewed at https://ijme.in/ . The advertisement rates are given below.

\section{For print:}

\begin{tabular}{|l|c|c|r|r|}
\hline \multicolumn{1}{|c|}{ Colour scheme } & Type & Dimension $(\mathrm{cm})$ & \multicolumn{2}{c|}{ Rates (in INR) } \\
\hline & & & Single issue & \multicolumn{1}{c|}{ Four issues } \\
\hline Black and white & Full page & 24 height x 18 width & 25000 & 85000 \\
\hline Black and white & Half page & 12 height x 18 width & 15000 & 50000 \\
\hline Black and white & Quarter page & 10 height x 8.8 width & 6500 & 25000 \\
\hline Colour cover - inside/outside & Full page & 24 height x 18 width & 40000 & 125000 \\
\hline
\end{tabular}

Format of the images: High resolution; jpeg/png/gif/tiff

Single issue: quarter; four issues: whole year.

\section{For website:}

\begin{tabular}{|c|c|c|r|r|r|}
\hline Type & Dimension (pixels) & Placement & \multicolumn{3}{|c|}{ Rates (in INR) } \\
\hline & & & $\begin{array}{c}\text { One month } \\
\text { (30 days) }\end{array}$ & One quarter & One year \\
\hline Banner & 60 height x 832 width & $\begin{array}{c}\text { Landscape view in between the } \\
\text { homepage }\end{array}$ & 20000 & 50000 & 200000 \\
\hline Box & 165 height $\times 257$ width* & Top right, below the navigation bar & 20000 & 50000 & 200000 \\
\hline
\end{tabular}

*In case of more matter, the height may be increased up to 180 pixels

Format of the images: High resolution; jpeg/png/gif/tiff 